\title{
FRICTION STIR WELDING OF STEEL
}

\author{
Mystica Augustine Michael Duke ${ }^{1}$ \\ ${ }^{1}$ Final year student, Mechanical Engineering, CEG, Anna university, Chennai, Tamilnadu, India
}

\begin{abstract}
A water cooled holder has been designed to facilitate Friction stir welding of steel, which is not possible now because of the tool material limitations such as high temperature and load gradients, excess heat flow. Due to its high melting point, friction stir welding of steel generates very large amount of heat which has deleterious effect on the machine bearing. Deformation and wear of tool, degeneration of spindle bearing are some of the effects of FSW on steel which gradually destroys the whole system. To overcome these defects, a cooling system is needed to manage the heat transfer. A liquid cooled tool holder with a thermocouple, sealing and a coolant is designed and developed that manages heat removal from the tool. This article primarily focuses on the necessity and the layout of water cooled tool holder, selection of coolant and tool material. The results obtained show the increase in feasibility of friction stir welding of steel.
\end{abstract}

Keywords: Friction stir welding, FSW of steel, Water cooled tool holder, Tool steel, Coolant $* * *$

\section{INTRODUCTION}

Due to the high melting point of steel, the FSW tool develops huge amount of heat. The water cooled Tool Holder uses a cooling system which pulls the heat from the tool, keeping it at a steady temperature, allowing for better quality welds and improved tool life. FSW is a solid state joining process that has been described as one of the most significant advances in joining technology in the last fifty years (Ref. 5).Friction-stir welding is a solid-state joining process that uses a third body tool to join two facing surfaces. Heat is generated between the tool and material which leads to a very soft region near the FSW tool. It then mechanically intermixes the two pieces of metal at the place of the joint, then the softened metal can be joined using mechanical pressure (which is applied by the tool), much. It is primarily used on aluminium, and on structures which need superior weld strength without a post weld heat treatment (Ref. 7)

FSW is a highly reliable and efficient metal joining process where the metal adjacent to the weld joint is subjected to severe thermal conditions. As a result, complex changes in metallurgical structure occur in this region. These changes in structure depend on the material and the temperature experienced(Ref.8). This temperature depends upon the melting point of the material used. For aluminium the melting point is $660.3^{\circ} \mathrm{C}$ Thermocouple measurements during FSW of aluminiumThe O-ring may be used in static applications or in dynamic applications where there is relative motion between the parts and the O-ring. The Oring may be used in static applications or in dynamic applications where there is relative motion between the parts and the O-ring. For aluminium alloys, in general, the temperature stays below $500^{\circ} \mathrm{C}$ (Ref. Hence $\mathrm{FSW}$ of aluminium is carried out successfully and safely

The variables that govern the FSW process are temperature, load, tool travel speed, spindle speed, tool design, thermal conductivity, melting point and thermal conductivity of weld material and heat transfer characteristics of the system. Aluminium alloys can be friction stir welded using a broad range of variable processes because of their low strength, high ductility and high thermal conductivity.But in case of steel, FSW has not been made easily possible yet. This is because of the very high melting point of steel which is $1370^{\circ} \mathrm{C}$.During welding, the tool shoulder reached a bright orange color which indicated an approximate temperature of over $1000^{\circ} \mathrm{C}$, within a few seconds of making contact. Also as the tool travels along the seam, the ensuing weld track behind the trailing edge of the rotating tool appeared orange/bright red $\left(900-1000^{\circ} \mathrm{C}\right)$ (Ref. 7). Due to this, the tool is more involved in managing heat flow rather than welding the material.The heat generated is detrimental to the system components. To remove the heat and to maintain a stable thermal environment in the system, a water cooled tool holder was designed. 


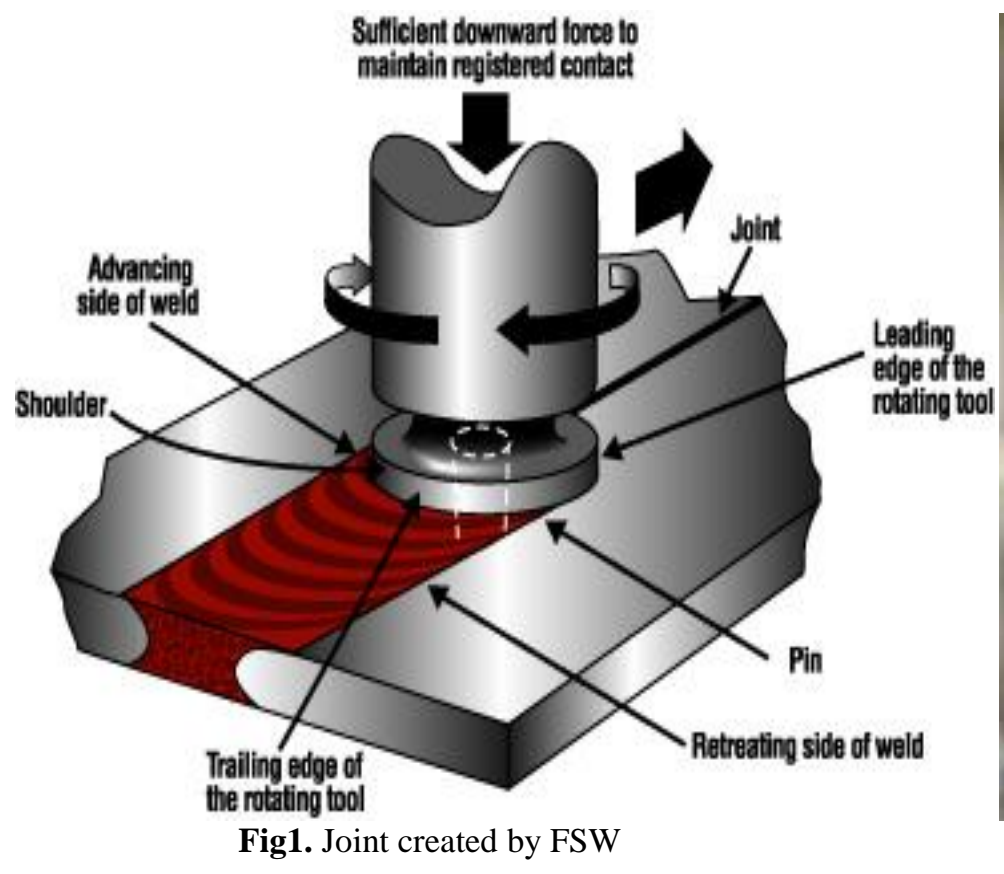

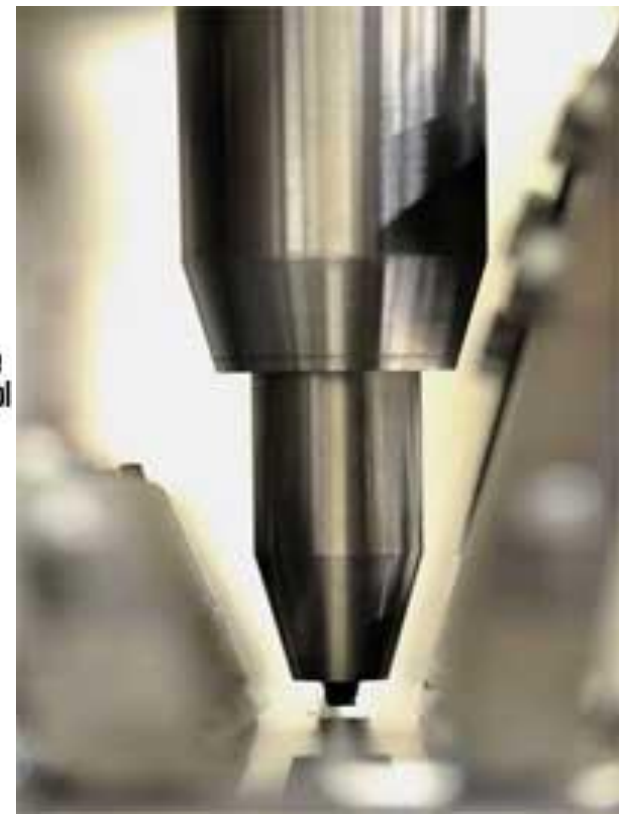

Fig2. PCBN Tool tip

\section{EXPERIMENTAL DETAILS}

Friction stir welding is highly advantageous when compared to many other welding processes like arc welding, and oxy fuel welding. Friction stirwelds often exhibit improved mechanical properties relative to those of fusion welds on the same material (Ref. 1). Till date, friction stir welding has been successfully applied in aluminium alloys (Ref 2 ). Since aluminum has been welded successfully, the focus has now turned towards FSW of steels (Ref. 3)It has been proved through research that FSW of steel is very difficult when compared to aluminium.(Ref.4)

The earliest research in FSW was focused on low to medium softening temperature metals, such as aluminium, lead, magnesium and zinc. The fusion welding of steel usually results in solidification cracking, hydrogen induced cracking and reheat cracking (Ref. 5).To overcome the above problem, FSW is the advantageous alternative technique. Thomas (1999) first demonstrated the feasibility of friction stir welding of steels, a high softening temperature material, and much of the research since the initial feasibility studies has focused on development of appropriate pin tools and the effect of FSW on steel microstructure (e.g. Jashti et. al 2005 Ramasubramanian et. al 2005, Leinert et al 2003 and Steel et al 2005.)

\section{COMPONENTS OF THE COOLING SYSTEM}

A tool system with a water cooled tool holder is designed to function with any rigid load control machine to friction stir weld steel. .A normal FSW tool system consists of a polycrystalline cubic boron nitride (PCBN) tip, a locking collar, thermocouple and a tungsten carbide shank that can withstand high temperatures. But the new water cooled tool system consists of a PCBN tip, a locking collar, a thermocouple, a tool steel shank, cooling unit.

\subsection{PCBN Tip}

PCBN is selected over tungsten carbide for its high thermal stability, hardness, and strength at elevated temperatures. It is classified as a superabrasive material, and is suitable for an high temperature processesImportant tool material qualities include elevated temperature strength and stability, wear resistance, tool reactivity, fracture toughness and thermal expansion. The tool material should have higher melting temperature than the work material.Subsequent research into tool materials for high melting temperature alloys has developed polycrystalline cubic boron (PCBN) tools (Ref.5)

\subsection{Lockingcollar}

The locking collar transmits the torque from the shank to the tip during FSW. A blind hole on the collar is used for positioning a type $\mathrm{K}$ thermocouple (with the range from $-200{ }^{\circ} \mathrm{C}$ to $1350{ }^{\circ} \mathrm{C}$ ). A set screw holds the thermocouple firmly against the side of the PCBN tip, enabling consistent temperature readings while the tool is rotating.

\subsection{Shank and the Cooling Unit}

The length of the shank is extended appropriately to provide space for the water circulation. The shank is surrounded by a casing that encloses the coolant and the seal. The casing is provided with an inlet and an outlet to circulate water. The spring loaed seal prevents the seepage of water from the cooling unit length and also arrests the rotation of the casing while permitting shank rotation. Water must always be circulating inside the chamber before starting the spindle to prevent excessive seal wear. 


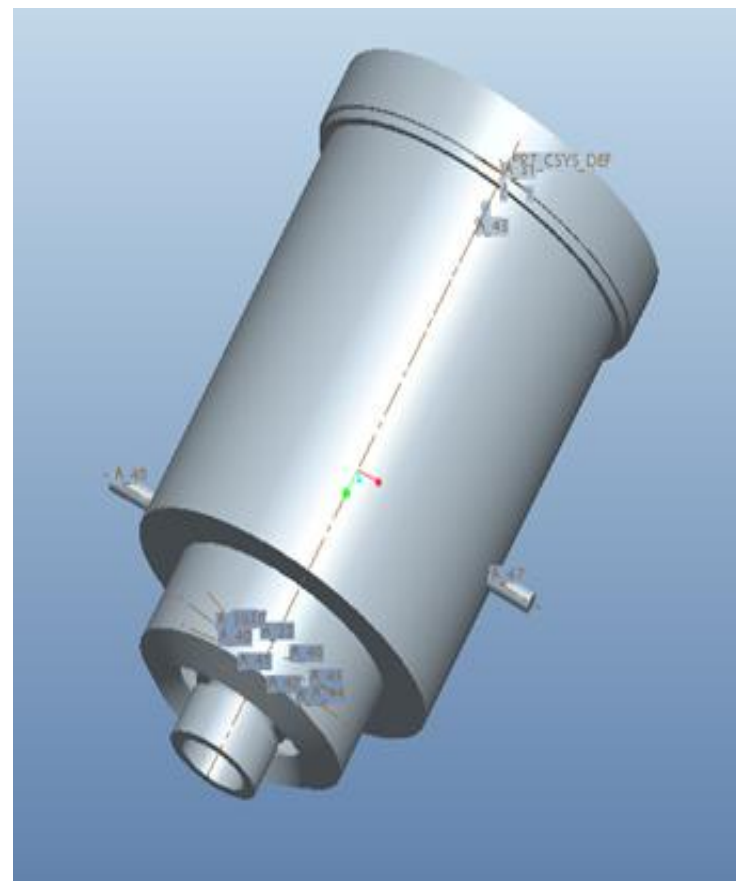

Fig 3 Tool holder (External view) with inlet and outlet for the coolant.

The workpiece made of steel is placed and welding is initiated with the cooling unit attached. Temperature is monitored with the help of thermocouple placed in the collar (around $800^{\circ} \mathrm{C}$ ), When the temperature exceeds the limit, coolant is turned on. The coolant (water) is pumped into the cooling unit through the inlet. Water is circulated throughout the chamber after which it vapourises. The steam is then condensed in a condenser and recirculated again.

\section{SPECIFICATIONS}

Tool steel for shank and casing: There are three primary properties of tool steel. They are toughness, wear resistance and heat resistance. A tool is in constant movement, either against another tool or work material. This constant movement can wear away the surface of the tool. The tool will need to have some amount of wear resistance. Tool steel shows resistant to corrosion by water. Hence the shank and the casing are made of tool steel.(Ref. 10)

Water as coolant: The advantages of using water cooling include water's higher specific heat capacity density, and thermal conductivity. This allows water to transmit heat over greater distances with much less volumetric flow and reducedtemperature difference. Water is inexpensive and non-toxic. (Ref. 13)

Spring loaded seal: The spring loaded seal can withstand a very high pressure of about $3.45 \mathrm{MPa}$. The rotation of the seal andcasing is arrested by using O-Ring.An O-ring is a mechanical gasket with a round cross-section, designed to be seated in a groove and compressed during assembly between two or more parts, creating a sealat the interface.The O-ring may be used in static applications or in

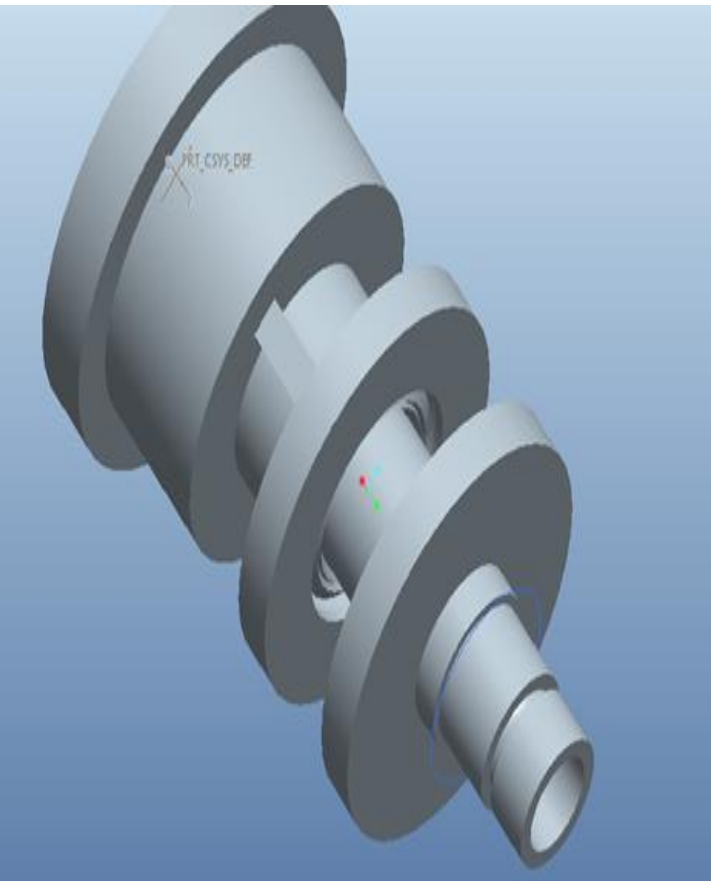

Fig 4 Tool holder inside the casing showing the cooling length with seal.

dynamic applications where there is relative motion between the parts and the O-ring. (Ref. 10).

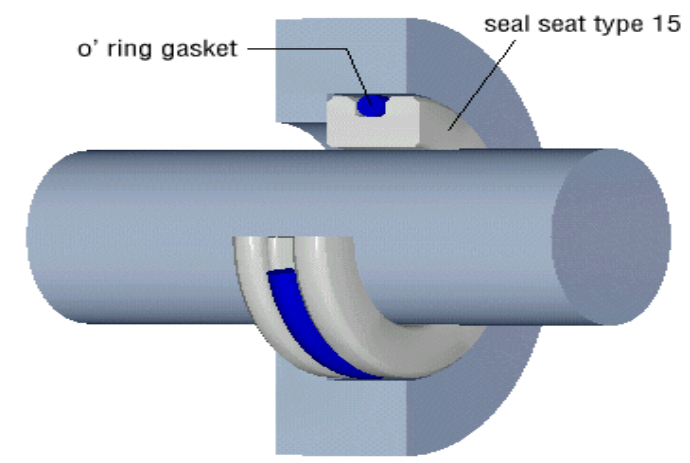

Fig5. Seal with the O-Ring

The water cooled tool holder has been designed to allow for steady state FSW load and temperature parameters. It maintains rigidity and precision during FSW applications.

\section{RESULTS AND DISCUSSIONS}

The microstructure and phase transformation of steels in FSW have not yet deeply studied and has been studied only through hardness test, impact toughness and tensile .Texture, fracture toughness, fatigue strength and elongation under load properties need to be completely analysed for FSW of steels [Ref.6]Research on FSW of steel has primarily been centered on industry driven applications with an emphasis on specialized steel alloys and stainless steels. As the technology becomes more commercially viable, knowledge of its application to traditional structural steels has the potential for application in steel construction; for example, FSW of steel could broaden the potential grades 
and combinations of steels used in structural applications, because FSW is particularly suitable to join highly dissimilar materials (Ref. 11). By expanding options for fabrication of steel members with the potential for increased fatigue strength and a reduction in residual stresses, FSW could provide new avenues for steel construction. The most important application of FSW in steel lies in the potential for joining high strength steels, since high strength steels are being used more and more frequently in structural applications. Significant cost savings have been achieved using higher strength steels. Common applications include off-shore oil platforms and long-span building structures. Another important advantage of FSW in steel is a reduction in weld distortion as compared to traditional fusion welds (Ref. 12). The main advantage is the reduction of hazardous fumes currently produced by arc welding thus proving to be eco-friendly Defalco enumerate a number of advantages for FSW in steel pipe welding including (but not limited to) time savings due to the use of single-pass full-penetration welds with no root pass required, significantly lower costs, elimination of the need for skilled welders, low distortion, adaptability to external environmental conditions, and reduction in defects. (Ref .12)

\section{REFERENCES}

[1]. Kinchen, D. G., Li, Z., and Adams, G. P. 1999. Mechanical properties of friction stir welds in Al-Li 2195T8. Proceedings of the FirstInternational Conference on Friction Stir Welding. Session 9, Paper 2. Cambridge, England:TWI.

[2]. Christner, B. K., and Sylva, G. D. 1996. Friction stir weld development for aerospaceapplications. Proceedings of ICAWT 1996, pp.311-320. EWI, Columbus, Ohio.

[3]. Thomas, W. M.,Threadgill, P. L. , and Nicholas, E. D. 1999. Feasibility of friction stir welding of steel. Science and Technology of Welding and Joining 4(6): 365-372.

[4]. Gould, J.E., Lienert, T.J. and Feng, Z., 1998,"Recent developments in friction stir welding," SAE Technical Paper Series 981875

[5]. FRICTION STIR WELDING OF STEEL CONNECTIONS Andrea E. Surovek

[6]. Threadgill PL, Johnson R. Progress in friction stir welding of steels. Technical report 815/2004. Great Abington,Cambridge ,UK: TWI (The Welding Institute); 2004.

[7]. A Review on Friction Stir Welding of Steel A. Pradeep Department of Metallurgical and Materials Engineering, NationalInstitute of Technology, Tiruchirapalli - 620015, Tamilnadu, India

[8]. Friction Stir Spot Welding of Advanced High-Strength Steels -A Feasibility Study Z. Feng, M. L. Santella, and S. A. David Metals and Ceramic Division, Oak Ridge National LaboratoryR.J. Steel and S. M. Packer MegaStir Technologies; T Pan Ford Research and Advanced Engineering, Ford Motor Company ; M. Kuo and R. S. Bhatnagar Ispat Inland Inc

[9]. New technique of filling friction stir welding Y. X. Huang*1, B. Han1, Y. Tian1, H. J. Liu1, S. X. Lv1, J. C. Feng1, J. S. Leng2 and Y. Li2

[10]. www.wikipedia.com
[11]. Friction stir welding of dissimilar metals: An overview - Mukuna .P.Mubiayi and Esther T.Akinlabi.

[12]. Friction Stir Welding Studies on Mild Steel Process results, microstructures, and mechanical properties are reported BY T. J. LIENERT, W. L. STELLWAG, JR., B. B. GRIMMETT, AND R. W. WARKE

[13]. www.enotes.com

\section{BIOGRAPHIE}

Mystica Augustine Michael Duke has received Master diplomo in PRODUCT DESIGN AND ANALYSIS and Bachelor of arts and Bachelor of education in HINDI. She is currently pursuing her Bachelor of Engineering in Mechanical Engineering in CEG, Anna university. 